\title{
Reactivity of Glycerol/Acetone Ketal (Solketal) and Glycerol/Formaldehyde Acetals toward Acid-Catalyzed Hydrolysis
}

\author{
Leonardo P. Ozorio, ${ }^{a, b}$ Rafael Pianzolli, ${ }^{a, b}$ Maria Beatriz S. Mota ${ }^{a, b}$ and \\ Claudio J. A. Mota*,a,b \\ ${ }^{a}$ Escola de Química, Universidade Federal do Rio de Janeiro, Av. Athos da Silveira Ramos, 149, \\ CT Bloco E, 21941-909 Rio de Janeiro-RJ, Brazil \\ ${ }^{b}$ INCT Energia Ambiente, Universidade Federal do Rio de Janeiro, Escola de Química, \\ Av. Athos da Silveira Ramos, 149, Bloco E, 21941-909 Rio de Janeiro-RJ, Brazil
}

Foi investigado o efeito da temperatura, razão molar e quantidade de catalisador na hidrólise ácida do cetal de glicerol/acetona (solketal) e acetais de glicerol/formaldeído. A reatividade do solketal foi bem maior que a dos acetais de glicerol/formaldeído. A $80^{\circ} \mathrm{C}, 5: 1$ de razão molar água/ cetal e uma quantidade de catalisador correspondendo a 3.0 mmol de sítios ácidos (amberlyst-15), a hidrólise do solketal foi praticamente quantitativa, enquanto os acetais de glicerol/formaldeído apresentaram cerca de $40 \%$ de conversão. A maior reatividade do solketal para hidrólise pode ser associada à formação de um carbocátion terciário como intermediário, enquanto no caso dos acetais de glicerol/formaldeído a hidrólise acontece via deslocamento nucleofílico direto. Cálculos teóricos no nível DFT sobre a estabilidade relativa dos acetais e cetais com anéis de cinco e seis membros explicam a distribuição experimental dos isômeros.

The effect of temperature, molar ratio and catalyst loading on the acid-catalyzed hydrolysis of glycerol/acetone ketal (solketal) and glycerol/formaldehyde acetals was studied. The reactivity of the solketal was significantly higher than the glycerol/formaldehyde acetals. At $80{ }^{\circ} \mathrm{C}, 5: 1$ water/ketal molar ratio and $3.0 \mathrm{mmol}$ of catalyst loading (amberlyst-15) the hydrolysis of the solketal was almost complete, whereas the glycerol/formaldehyde acetals showed around $40 \%$ conversion. The higher reactivity of solketal toward hydrolysis is associated with the formation of a tertiary carbocation intermediate, whereas in the case of glycerol/formaldehyde acetals hydrolysis takes place through direct nucleophilic displacement. DFT theoretical calculations of the relative stability of the ketal and acetal isomers, having five and six-membered rings, explain the experimental distribution.

Keywords: glycerol, biodiesel, hydrolysis, solketal, acetals

\section{Introduction}

Biodiesel is one of the main biofuels used worldwide. It is produced through the transesterification of vegetable oils or animal fat with methanol, under base catalysis conditions. ${ }^{1}$ In this process, glycerol or glycerin is formed as byproduct in approximately $10 \mathrm{wt} \%$. The overall world production of glycerin from biodiesel processing is estimated to reach 1.2 million tons by $2012,{ }^{2}$ but the forecast points to a much higher value in the future, due to the widespread production of this biofuel.

In Brazil, biodiesel is presently blended with the petrodiesel in $5 \%(\mathrm{v} / \mathrm{v})$, yielding approximately 250

*e-mail: cmota@iq.ufrj.br thousand tons of glycerin per year. This value is much higher than the glycerin market in Brazil, in the order of 30 thousand tons per year, and it is imperative to the economical feasibility of the biodiesel program to drain this excess of glycerin. Personal care products, soaps, pharmaceuticals and foods are the main sectors that make regular use of glycerin. However, they cannot absorb, alone, all the glycerin produced from the biodiesel industry. Thus, it is necessary to find new applications for this excess of glycerin produced by the biodiesel industry.

The use of glycerin as a raw material to produce other chemicals is gaining interest in recent years. ${ }^{3-5}$ Hydrogenolysis over metal catalysts affords 1,2 and 1,3-propanediols, which can be used in the production of polymers. ${ }^{6,7}$ Dehydration over acidic catalysts produces 
acrolein, ${ }^{8,9}$ an important intermediate in the synthesis of acrylic acid and other chemicals. Synthesis gas, a mixture of $\mathrm{CO}$ and $\mathrm{H}_{2}$, can be produced from glycerol, ${ }^{10}$ opening the possibility to produce hydrocarbon in the diesel range, through Fischer-Tropsch synthesis. ${ }^{11}$

Glycerol can also be converted in ethers, acetals/ ketal and esters, all of them with potential to be used as fuel additives. For instance, the reaction of glycerol with isobutene affords tert-butyl-glyceryl ethers. ${ }^{12}$ Glycerol ethers can also be produced through acid-catalyzed reaction of glycerol with alcohols. ${ }^{13}$ Glycerol acetals and ketals can be produced through the acid-catalyzed reaction with aldehydes and ketones, respectively. ${ }^{14}$ These compounds can be blended with the biodiesel to improve the cold flow properties. ${ }^{15}$ Acetylation of glycerol affords the acetins or glycerol acetates, ${ }^{16,17}$ which have been tested as additives for the biodiesel. ${ }^{18}$

We have recently shown ${ }^{19}$ that solketal, the ketal produced in the reaction of glycerol with acetone, improves the octane number and reduces gum formation in gasolines, either with or without ethanol. Therefore, it can be a potential oxygenated gasoline additive, especially in Brazil, where the major part of the gasoline comes from catalytic cracking, yielding a product with high concentration of olefins and, by this way, more susceptible to gum formation.

Methyl-tert-butyl ether (MTBE) has been the most important gasoline additive in the 1990's, but its use has been phased out due to its carcinogenic properties, ${ }^{20}$ especially because of its accumulation in water sources. Thus, any potential additive should not be dangerous to humans or may be easily decomposed in the environment to prevent further damages. We wish to report in this study the reactivity of glycerol/acetone ketal (solketal) and the glycerol/formaldehyde acetals toward acid-catalyzed hydrolysis.

\section{Experimental}

The preparation of the glycerol/acetone ketal and glycerol/formaldehyde acetal was reported elsewhere. ${ }^{21}$ The reactivity studies were carried out in batch, stirring $54 \mathrm{mmol}$ of the ketal or acetal with a given amount of the acidic amberlyst- 15 catalysts to obtain 1.5 and $3.0 \mathrm{mmols}$ of acid sites. Amberlyst-15 acid resin has a concentration of acid sites of $4.2 \mathrm{mmol} \mathrm{g}^{-1}$. Different amounts of water, corresponding to a molar ratio of water to acetal or ketal of $0,1,5$ and 10 were added to the reaction medium, as well as $50 \mu \mathrm{L}$ of 1.4-dioxane, used as internal standard. The system was set to 40 or $80{ }^{\circ} \mathrm{C}$ during $6 \mathrm{~h}$ and the conversion was monitored throughout this period, by analyzing samples taken from the reaction medium. The analyses were carried out by gas chromatograph coupled with mass spectrum, to obtain the conversion and selectivity data.

Theoretical calculations were carried out at B3LYP/6-31G(d,p) level, using the Gaussian 09 program. ${ }^{22}$ The initial structures were subjected to geometry optimization. Harmonic frequency analysis were performed at the same level of calculation to obtain zero-point energies (ZPE) and thermal corrections at $298.15 \mathrm{~K}$, considering ideal gas approximation. These calculations were also used to obtain the thermodynamic data of the isomers.

\section{Results and Discussion}

The reaction of glycerol with acetone affords mainly one isomer, named (2,2-dimethyl-1,3-dioxolan-4-yl) methanol (solketal) (1), which is a five-membered ring (Scheme 1). On the other hand, the reaction of glycerol with formaldehyde solution affords a mixture of two isomers named (1,3-dioxolan-4-yl)methanol (2a) and 1,3-dioxan-5-ol (2b) (Scheme 2) in approximately 30 and $70 \%$ distribution. It is known that five-membered ring compounds are kinetically favorable, ${ }^{23}$ whereas sixmembered ring compounds are favored by thermodynamics. Thus, the first study involved the interconversion of the isomers in the presence of the acidic catalysts, without adding water. We did not observe any significant change in the isomer distribution of glycerol/acetone ketal (solketal) and glycerol/formaldehyde acetals at the conditions studied. Apparently, the thermodynamic distribution is achieved during the synthesis procedure, although in the case of solketal, one should expect that the six-membered ring isomer would be thermodynamically more stable and should be produced in higher extent in the presence of the acidic catalyst and longer reaction times. This was not observed even at $80^{\circ} \mathrm{C}$ in the presence of $3.0 \mathrm{mmol}$ of acid sites and $6 \mathrm{~h}$ of reaction time.

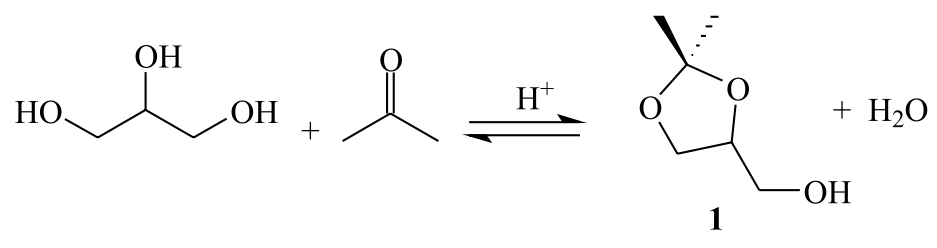

Scheme 1. Reaction of glycerol with acetone under acid catalysis conditions. 


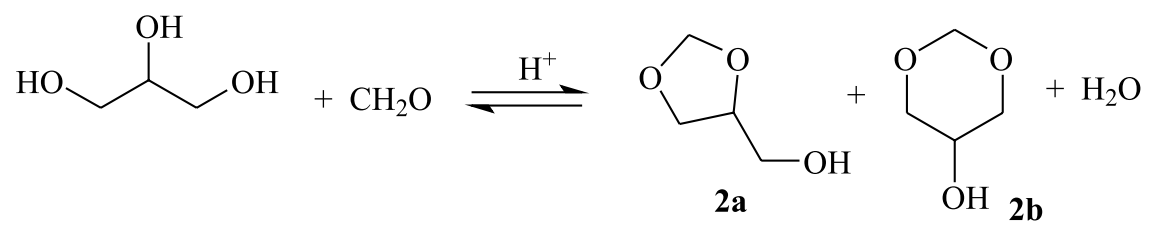

Scheme 2. Reaction of glycerol with formaldehyde under acid catalysis conditions.

To understand the reason for the distribution of the ketal and acetals isomers we carried out theoretical calculations at B3LYP/6-31G(d,p) level of theory. Figures 1 and 2 show the calculated structures and Table 1 gives the Gibbs free-energy difference at $298.15 \mathrm{~K}$. For the glycerol/formaldehyde acetals the results indicated that $\mathbf{2 b}$ is $0.7 \mathrm{kcal} \mathrm{mol}^{-1}$ lower in energy than the 2a isomer, in agreement with the higher stability of the six-membered ring. This energy difference corresponds to a distribution of $70 \%$ and $30 \%$ at $298.15 \mathrm{~K}$, in agreement with the experimental result. On the other hand, the results for the glycerol/acetone ketal indicated an opposite trend, with (2,2-dimethyl-1,3dioxolan-4-yl)methanol (1) being $1.7 \mathrm{kcal} \mathrm{mol}^{-1}$ more stable than 2,2-dimethyl-1,3-dioxan-5-ol, the six-membered ring isomer that was not observed in the reactions. This energy difference would afford an isomer distribution with about 95\% of (2,2-dimethyl-1,3-dioxolan-4-yl)methanol (1) at $298.15 \mathrm{~K}$, in good agreement with the experimental findings. The reason for the lower stability of the 2,2-dimethyl-1,3-dioxan-5-ol isomer is due to the methyl group in the axial position, which may repulsively interact

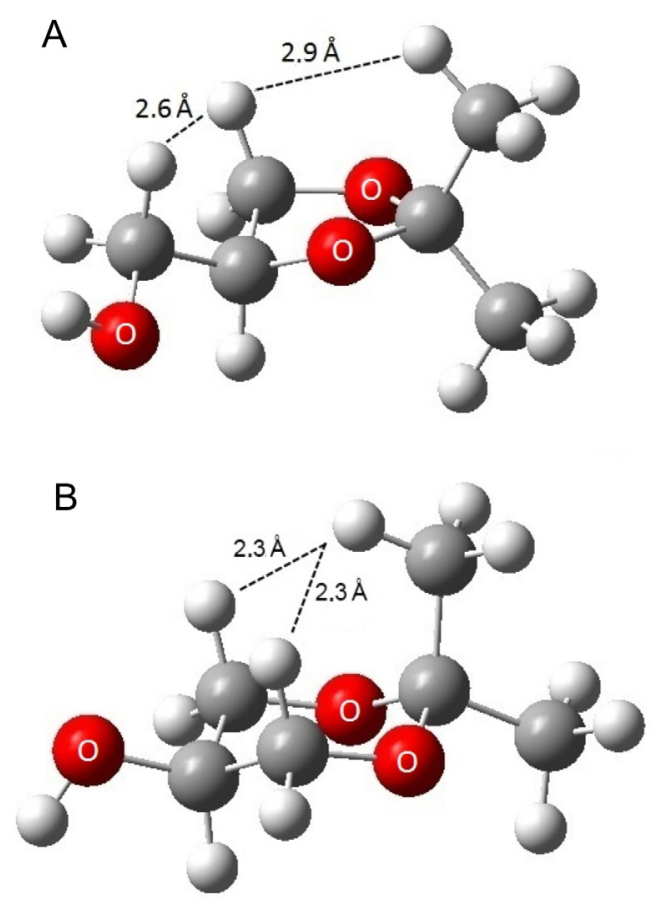

Figure 1. Calculated structure of the (2,2-dimethyl-1,3-dioxolan-4-yl) methanol (A) and 2,2-dimethyl-1,3-dioxan-5-ol (B) at B3LYP/6-31G(d,p). with the two hydrogen atoms in the other axial positions of the six-membered ring. This situation is minimized in the five-membered ring, as one can see from the calculated distances. The methyl group is closer to the axial hydrogen atom in the six-membered ring ketal (Figure 1B).
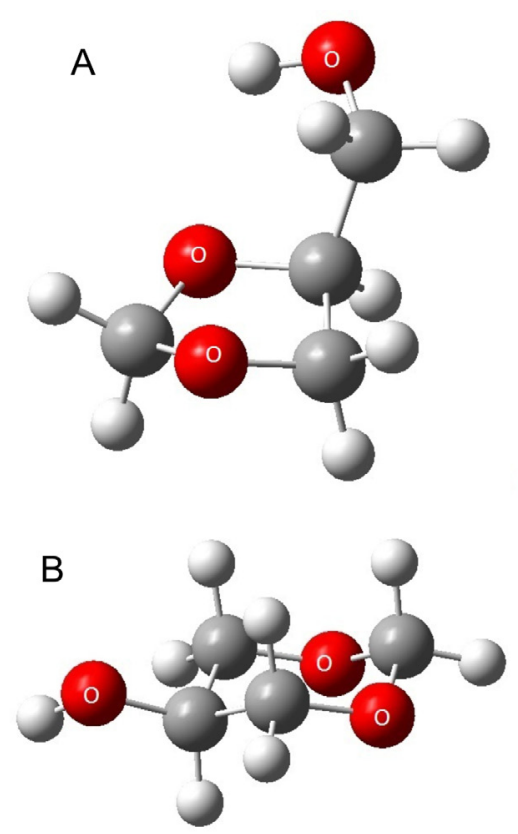

Figure 2. Calculated structure of (1,3-dioxolan-4-yl) methanol (A) and 1,3-dioxan-5-ol (B) at B3LYP/6-31G(d,p).

Table 1. Calculated ${ }^{a}$ Gibbs free-energy difference at $298.15 \mathrm{~K}$ for the glycerol/acetone ketals and glycerol/formaldehyde acetals

\begin{tabular}{lc}
\hline Compound & $\begin{array}{c}\Delta \mathrm{G}_{298} \text { difference / } \\
\left(\mathrm{kcal} \mathrm{mol}^{-1}\right)\end{array}$ \\
\hline $\begin{array}{l}\text { Glycerol/acetone ketals } \\
\text { (2,2-dimethyl-1,3-dioxolan-4-yl)methanol }\end{array}$ & 0 \\
2,2-dimethyl-1,3-dioxan-5-ol & \\
Glycerol/formaldehyde acetal $^{\mathrm{b}}$ & 1.7 \\
(1,3-dioxolan-4-yl) methanol & \\
1,3-dioxan-5-ol & 0.7 \\
\hline
\end{tabular}

${ }^{\mathrm{a} C a l c u l a t i o n s}$ at B3LYP/6-31G(d,p) level. ${ }^{\text {bSee Figure } 1 \text { for structures. }}$ 'See Figure 2 for structures.

Table 2 shows the conversion after $6 \mathrm{~h}$ of reaction time for the acid-catalyzed hydrolysis of solketal as a function of temperature, acid site concentration and water molar content. At $80^{\circ} \mathrm{C}$, even in the absence of catalyst, there is a significant decomposition of this compound in excess 
Table 2. Acid-catalyzed hydrolysis of solketal. Conversion after $6 \mathrm{~h}$

Reaction Temperature $/{ }^{\circ} \mathrm{C}$

\begin{tabular}{|c|c|c|c|c|c|c|}
\hline \multirow{3}{*}{ Catalyst Loading $^{\mathrm{a}}$} & \multicolumn{3}{|c|}{80} & \multicolumn{3}{|c|}{40} \\
\hline & \multicolumn{3}{|c|}{ Water:solketal molar ratio } & \multicolumn{3}{|c|}{ Water:solketal molar ratio } \\
\hline & $1: 1$ & $5: 1$ & $10: 1$ & $1: 1$ & $5: 1$ & $10: 1$ \\
\hline $0 \mathrm{mmol}$ & 0 & 89 & 92 & 0 & 0 & 22 \\
\hline $1.5 \mathrm{mmol}$ & 80 & 96 & 99 & 54 & 89 & 96 \\
\hline $3.0 \mathrm{mmol}$ & 73 & 99 & - & 35 & 93 & 96 \\
\hline
\end{tabular}

${ }^{\mathrm{a}}$ Expressed in terms of amount of acid sites.

of water, indicating its great reactivity toward hydrolysis. The addition of catalyst speeds up the reaction, which is almost complete when using 5:1 molar ratio of water to ketal and $3.0 \mathrm{mmol}$ of acid sites. Figure 3 shows the kinetics of the hydrolysis at $80{ }^{\circ} \mathrm{C}$ and $1.5 \mathrm{mmol}$ of acid sites, for different water proportions. One can see that within the first $50 \mathrm{~min}$, the conversion increases sharply and practically attains a constant value in the case of higher water contents. At $40{ }^{\circ} \mathrm{C}$, the behavior is similar but the conversions are somewhat lower.

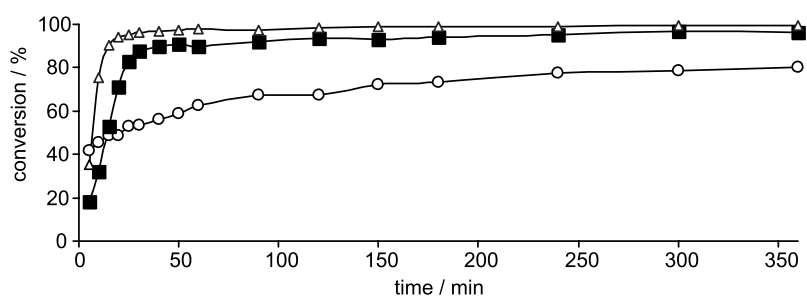

Figure 3. Kinetics of the solketal hydrolysis at $80{ }^{\circ} \mathrm{C}$ in the presence of $1.5 \mathrm{mmol}$ of acid sites of amberlyst-15 and different water:ketal molar ratios. (○) $1: 1 ;(\mathbf{\square}) 5: 1 ;(\triangle) 10: 1$

Table 3 shows the results of acid-catalyzed hydrolysis of the glycerol/formaldehyde acetal isomers as a function of temperature, acid site concentration and water content. One can see that the reactivity is significantly lower, when compared to the glycerol/acetone ketal. No appreciable conversion was observed in the absence of catalyst, even at $80{ }^{\circ} \mathrm{C}$ and a large excess of water. The highest conversions were achieved for higher catalyst loading, but the water content does not significantly affect the final value after $6 \mathrm{~h}$ of reaction. At $40^{\circ} \mathrm{C}$ the reaction is significantly slower and fluctuations may occur. Figure 4 shows the kinetics of the acid-catalyzed hydrolysis at $80^{\circ} \mathrm{C}$, using $3.0 \mathrm{mmol}$ of acid sites and different water content. One can see that hydrolysis is significantly slower when compared with solketal and even after $6 \mathrm{~h}$ there are significant amounts of the acetals in the medium. It is interesting to note that reaction proceeds faster for the lower water:acetal molar ratio. This may be explained in terms of the acid strength of the amberlyst catalyst in the presence of water. As the concentration of water increases in the medium, the acid sites may be weakened due to adsorption of the water molecules on the acid sites. Thus, the reaction proceeds slower, although in all cases a similar conversion was achieved after $6 \mathrm{~h}$ of reaction. These results indicate that the formation of glycerol/formaldehyde acetals requires stronger acid sites than formation of solketal, as might be anticipated from the results of a previous study. ${ }^{21}$

We may explain the different reactivities based on the proposed mechanistic pathway (Scheme 3). Whereas solketal formation and hydrolysis involves a tertiary

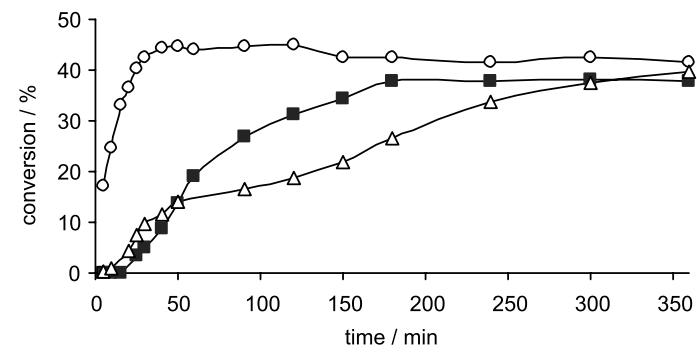

Figure 4. Kinetics of the glycerol/formaldehyde hydrolysis at $80{ }^{\circ} \mathrm{C}$ in the presence of $3.0 \mathrm{mmol}$ of acid sites of amberlyst-15 and different water:ketal molar ratios. (○) $1: 1 ;(\square) 5: 1 ;(\triangle) 10: 1$.

Table 3. Acid-catalyzed hydrolysis of glycerol/formaldehyde acetals. Conversion after $6 \mathrm{~h}$

Reaction Temperature $/{ }^{\circ} \mathrm{C}$

80

Water:acetals molar ratio

Catalyst Loading ${ }^{\mathrm{a}}$

$0 \mathrm{mmol}$

$1.5 \mathrm{mmol}$

$3.0 \mathrm{mmol}$

${ }^{\mathrm{a}}$ Expressed in terms of amount of acid sites.

40

Water:acetals molar ratio

\begin{tabular}{cccccc}
$n$ & $5: 1$ & $10: 1$ & $1: 1$ & $5: 1$ & $10: 1$ \\
0 & 0 & 0 & 0 & 0 & 0 \\
23 & 36 & 35 & 17 & 4 & 11 \\
42 & 38 & 40 & - & - & - \\
\hline
\end{tabular}


carbocation, hydrolysis of glycerol/formaldehyde acetals involves a direct displacement with nucleophilic attack by water. This is because a primary carbocation would be significantly high in energy and it would not be formed. Since the medium is highly polar and poorly nucleophilic, the pathway involving the carbocation is preferred, explaining the higher hydrolysis rate of solketal in comparison with the glycerol/formaldehyde acetals.

The potential use of solketal as gasoline additive ${ }^{19}$ raises the concern of its environmental risks, especially upon contamination of water sources. The results clearly show that hydrolysis of solketal is favorable and that this chemical would not persist in water, being decomposed to glycerol and acetone. This behavior is different from
MTBE, which is persistent in water and may be eventually absorbed by humans, causing health problems. ${ }^{24}$

The gas chromatographic analysis of the glycerol/ formaldehyde hydrolysis indicated the presence of at least four peaks at significantly longer retention times. The mass spectrum analysis showed that the four components have similar fragmentation patterns, indicating that they are all isomers. The most intense peaks were observed at $m / z 71,87,117$ and 147 . The four compounds were identified as ethers formed upon the reaction of the glycerol/formaldehyde acetals with glycerol produced upon hydrolysis (Scheme 4). Besides the mass spectrum analysis, the identity of the compounds was confirmed in a control experiment. Glycerol was reacted with

\section{Glycerol/acetone system}

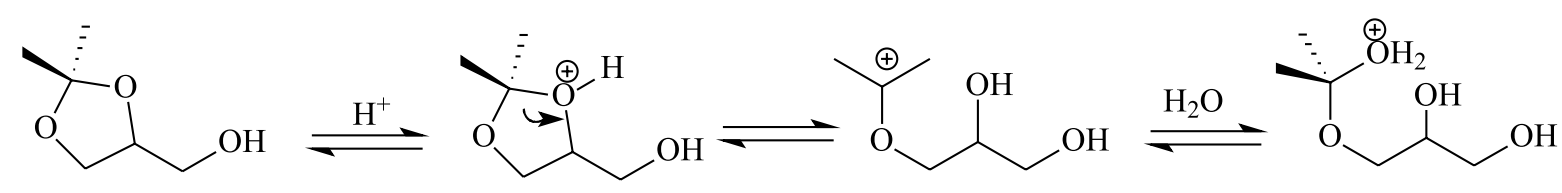

\section{Glycerol/formaldehyde system}<smiles>C=C=C[In]CC1COCO1</smiles><smiles>OCC1COCO1</smiles><smiles>OCOCC(O)CO</smiles><smiles>OC1COCOC1</smiles><smiles>C=CO</smiles><smiles>OCOCC(O)CO</smiles>

Scheme 3. Proposed mechanistic pathway for the acid-catalyzed hydrolysis of glycerol/acetone ketal and glycerol/formaldehyde acetals showing the formation of the hemi-ketal and hemi-acetal, respectively.

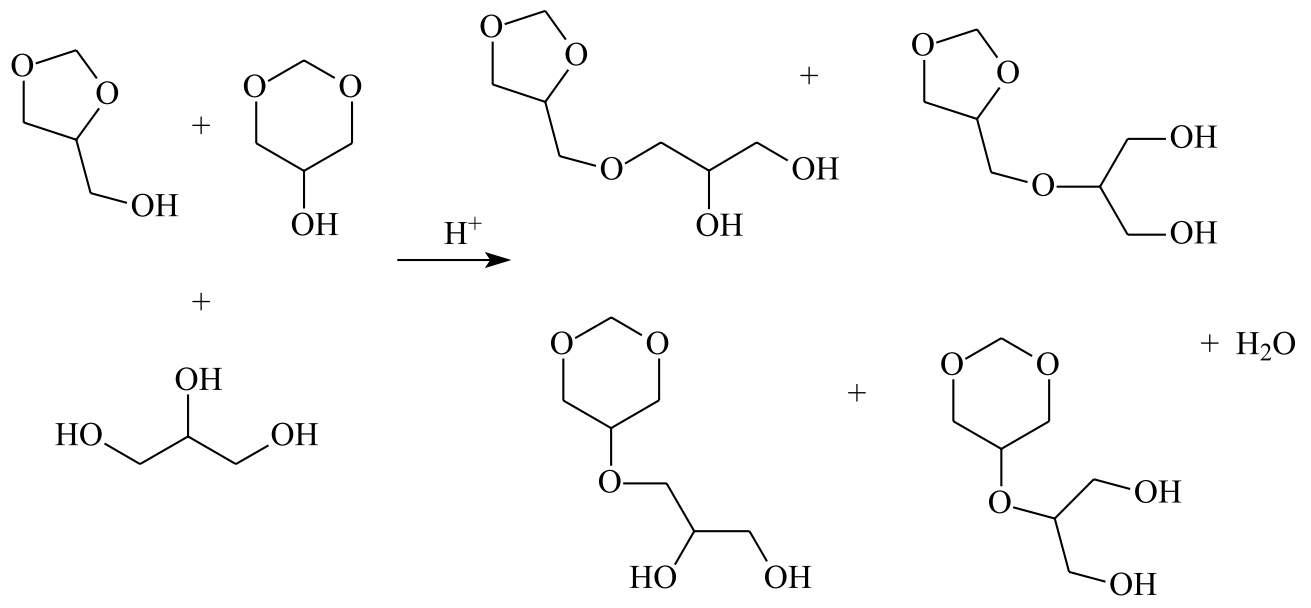

Scheme 4. Etherification of the glycerol/formaldehyde acetals. 
the acetal isomers at the same conditions of catalyst loading, temperature and reaction time affording the same four peaks in the chromatogram, with the same mass spectrum fragmentation pattern. The formation of glycerol ethers upon reaction with alcohols has already been reported in the literature. ${ }^{25,26}$ The remaining hydroxyl group of the acetals behaves as an alcohol and can react with the formed glycerol, upon acid catalysis conditions. These results reinforce the lower reactivity of the glycerol/formaldehyde acetals toward acid-catalyzed decomposition. Amberlyst-15 is among the most active catalysts for the acid-catalyzed etherification of glycerol with alcohols. ${ }^{27}$ The same type of products was not observed in the case of solketal, because of its fast hydrolysis.

\section{Conclusions}

The acid-catalyzed hydrolysis of glycerol/acetone ketal (solketal) and glycerol/formaldehyde acetals showed a remarkable difference in reactivity. Solketal is significantly more reactive than the glycerol/formaldehyde acetals, indicating that it can be easily decomposed in the environment, especially in water sources.

The higher reactivity of solketal toward hydrolysis may be explained in terms of the proposed reaction mechanism, which involves a tertiary carbocation intermediate.

Theoretical calculations showed that (2,2-dimethyl-1,3dioxolan-4-yl)methanol (solketal) is thermodynamically more stable than the 2,2-dimethyl-1,3-dioxan-5-ol isomer. This is due to steric repulsions associated with the presence of the methyl group in axial position of the six-membered ring. By contrast, for the glycerol/formaldehyde acetal the situation is the opposite, with the (1,3-dioxolan-4-yl) methanol (2a) being higher in energy than the 1,3-dioxan-5-ol isomer. The calculated energy difference is in agreement with the isomer distribution found experimentally.

\section{Acknowledgments}

Authors thank FINEP, FAPERJ and CNPq for financial support.

\section{References}

1. Meher, L. C.; Sagar, D. V.; Naik, S. N.; Renew. Sustain. Energ. Rev. 2006, 10, 248; Luque, R.; Lovett, J. C.; Datta, B; Clancy J.; Campelo, J. M.; Romero, A. A.; Energy Environ. Sci. 2010, 3, 1706 .

2. Zhou, C. H.; Beltramini, J. N.; Fan, Y. X.; Lu, G. Q.; Chem. Soc. Rev. 2008, 27, 527.
3. Pagliaro, M.; Ciriminna, R.; Kimura, H.; Rossi, M.; Pina, C. D.; Angew. Chem., Int. Ed. 2007, 46, 4434.

4. Behr, A.; Eilting, J.; Irawadi, K.; Leschinski, J.; Lindner, F.; Green Chem. 2008, 10, 13.

5. Jérôme, F.; Pouilloux, Y.; Barrault, J.; ChemSusChem 2008, 1, 586.

6. Dasari, M. A.; Kiatsimkul, P. P.; Sutterlin, W. R.; Suppes, G. J.; Appl. Catal., A 2005, 281, 225.

7. Kusunoki, Y.; Miyazawa, T.; Kunimori, K.; Tomishige, K.; Catal. Commun. 2005, 6, 645.

8. Chai, S. H.; Wang, H. P.; Liang, Y.; Xu, B. Q.; J. Catal. 2007, $250,342$.

9. Tsukuda, E.; Sato, S.; Takahashi, R.; Sodesawa, T.; Catal. Commun. 2007, 8, 1349.

10. Soares, R. R.; Simonetti, D. A.; Dumesic, J. A.; Angew. Chem., Int. Ed. 2006, 45, 3982.

11. Simonetti, D. A.; Rass-Hansen, J.; Kunkes, E. L.; Soares, R. R.; Dumesic, J. A.; Green Chem. 2007, 9, 1073.

12. Klepacova, K.; Mravec, D.; Bajus, M.; Appl. Catal., A 2005 , 294, 141.

13. Gu, Y.; Azzouzi, A.; Pouilloux, Y.; Jerome, F.; Barrault, J.; Green Chem. 2008, 10, 164.

14. Deusch, J.; Martin, A.; Lieske, H.; J. Catal. 2007, 245, 428.

15. Silva, P. H. R.; Gonçalves, V. L. C.; Mota, C. J. A.; Bioresour. Technol. 2010, 101, 6225 .

16. Gonçalves, V. L. C.; Pinto, B. P.; da Silva, J. C.; Mota, C. J. A.; Catal. Today 2008, 133-135, 673.

17. Silva, L. N.; Gonçalves, V. L. C.; Mota, C. J. A.; Catal. Commun. 2010, 11, 1036.

18. Garcia, E.; Laca, M.; Perez, E.; Garrido, A.; Peinado, J.; Energy Fuels 2008, 22, 4274.

19. Mota, C. J. A.; da Silva, C. X. A.; Rosenbach Jr., N.; Costa, J.; da Silva, F.; Energy Fuels 2010, 24, 2733.

20. Nadim, F.; Zack, P.; Hoag, G. E.; Liu, S. L.; Energ. Pol. 2001, $29,1$.

21. da Silva, C. X. A.; Gonçalves, V. L. C.; Mota, C. J. A.; Green Chem. 2009, 11, 38.

22. Frisch, M. J.; Trucks, G. W.; Schlegel, H. B.; Scuseria, G. E.; Robb, M. A.; Cheeseman, J. R.; Scalmani, G.; Barone, V.; Mennucci, B.; Petersson, G. A.; Nakatsuji, H.; Caricato, C.; Li, X.; Hratchiean, H. P.; Izmaylov, A. F.; Bloino, J.; Zheng, G.; Sonnenberg, J. L.; Hada, M.; Ehara, M.; Toyota, K.; Fukuda, R.; Hasegawa, J.; Ishida, M.; Nakajima, T.; Honda, Y.; Kitao, O.; Nakai, H.; Vreven, T.; Montgomery, J.A.; Peralta, J.E.; Ogliaro, F.; Bearpark, M.; Heyd, J. J.; Brothers, E.; Kudin, K. N.; Staroverov, V. N.; Kobayashi, R.; Normand, J.; Raghavachari, K.; Rendell, A.; Burant, J. C.; Iyengar, S. S.; Tomasi, J.; Cossi, M.; Rega, N.; Millam, J. M.; Klene, M.; Knox, J. E.; Cross, J. B.; Bakken. V.; Adamo, C.; Jaramillo, J.; Gomperts, R.; Stratmann, R. E.; Yazyev, O.; Austin, A. J.; Cammi, R.; Pomelli, C.; Ochterski, J. W.; Martin, R. L.; Morokuma, K.; Zakrzewaki, V. G.; Voth, 
V. A.; Salvador, P.; Dannenberg, J. J.; Dapprich, S.; Daniels, A. D.; Farkas, O.; Foresman, J. B.; Ortiz, J. V.; GAUSSIAN 09, Revision A.2; Gaussian Inc.: Wallingford CT, 2009.

23. Chandrasekhar, S.; Chem. Soc. Rev. 1987, 16, 313.

24. Ahmed, F. E.; Toxicol. Lett. 2001, 123, 89.

25. Klepacova, K.; Mravec, D.; Hajekova, E.; Bajus, M.; Petroleum and Coal 2003, 45, 54.
26. Pariente, S.; Tanchoux, N.; Fajula, F.; Green Chem. 2009, 11, 1256.

27. da Silva, C. R. B.; Gonçalves, V. L. C.; Lachter, E. R.; Mota, C. J. A.; J. Braz. Chem. Soc. 2009, 20, 201.

Submitted: December 13, 2011

Published online: April 19, 2012 